\title{
Left Dislocation: An exploration in linguistic typology
}

\author{
Alexander Andrason \\ Department of African Languages, Stellenbosch University, South Africa \\ E-mail: andrason@sun.ac.za \\ Josh Westbury \\ Department of Ancient Languages, Stellenbosch University, South Africa | Faithlife Corporation (Logos Bible \\ Software), USA \\ E-mail: josh.westbury@gmail.com
}

Christo H. J. van der Merwe

Department of Ancient Languages, Stellenbosch University, South Africa

E-mail: cvdm@sun.ac.za

\section{From the Left Dislocation problem to this volume's "solution"}

In recent years, Left Dislocation (LD), and the related notion of constituent order, received much attention from both generative and cognitive-functional perspectives. The former has generally focused on formal properties of LD, while the latter has focused on the range of discourse-pragmatic functions associated crosslinguistically with this type of structure. Although each framework continues to yield valuable insights into the nature of LD across languages, a typologically comprehensive explanation of the construction continues to elude linguists from both generative and cognitive-functional perspectives. A primary reason for this is found in the inherent limitations that have constrained each framework. Generativists, on the one hand have gradually acknowledged that it is nearly impossible to describe a LD construction adequately without taking its functional dimension into account. On the other hand, functional scholars pay more attention to the structure of LD and, especially, to its formal contrast with, or in relation to, other constructions (see, Andrason 2016c\&d; Andrason and Visser 2016). As a result, the need for a more unified formal-functional approach to LD has become increasingly evident.

Although the entanglement of form and function is acknowledged by most linguists (both from generative and functional schools) who study LD, there is another question that still divides the two schools: what constitutes the typological profile of the grammatical category of LD, both in terms of form and function? This question relates to a more general debate polarizing generative grammar and cognitive linguistics, viz. the issue of categorization. The two approaches understand categories differently. In general terms, generative linguists tend to advocate for a set of criteria that a construction must meet in order to qualify as an instance of a given category. In contrast, cognitive linguists argue that a category should rather be described and analyzed by making use of family-resemblance relationships. Although the prototype is 
defined by a set of criteria (as is done in the generative framework), the category as such is not. The category rather constitutes a radial network whose members may comply with all or some properties identified for the prototype. Importantly, no property is viewed as essential and/or compulsory.

The two fundamental views on categorization outlined above lead to further discrepancies between the two frameworks. In generative grammar, category membership is formulated in terms of a binary opposition - a construction either is a member of a category or it is not. In cognitive linguistics, however, category membership is formulated in multivalent (or even fuzzy) terms of gradual compliance or similarity. In other words, constructions "belong” to a category to a greater or lesser extent. This unequal category status of different members stems from the radial structure of the category. Central members are canonical instantiations. They comply with the prototype to a large degree, thus being representative of the class. In contrast, peripheral members are non-canonical. They exhibit only some features postulated for the prototype, representing the category to a lesser extent. As non-canonical instantiations further diverge from the prototype, they become even less representative. In other words, instantiations may exhibit increasingly fewer prototypical criteria, inversely exhibiting multiple traits that are not associated with the prototype. It is in these regions that categories overlap and the fuzziness of their borders appears. That is, non-canonical members of a category that exhibit characteristics linking them to more than one prototype, belong to multiple category networks. Since the similarity with one prototype decreases gradually (as fewer prototypical features are present), while the compliance with the other prototype inversely increases in an equally gradual manner (as more features are present), the change from one category to another is scalar. Therefore, any line that would separate members that exhibit mixed properties and include them in only one of the two categories to which they are linked, is arbitrary and artificial. Category borders are fuzzy (for the most recent comprehensive overview of a cognitive approach, consult Janda 2015). This contrasts with a generative approach in which categories are discrete, given the binary operation determining whether a given instantiation is to be included in it or not.

These contrasting approaches to the nature of grammatical categories reflects a more fundamental difference between the two frameworks. Cognitive linguists argue that the radial and gradient structure of a category results from the inherent dynamic nature of language, where synchrony and diachrony are closely related. In this view, synchrony is an expression of diachronic forces that underlie it. A synchronic view of language should not be thought of as snap shot, a motionless picture, but rather as a fully mobile account of an evolving object. This contrasts with a static analysis of synchrony assumed by the generative program, where language change is generally ignored at the synchronic level of analysis. In short, diachrony and synchrony are conceptually separated in generative grammar, synchrony being a motionless representation of a language at a given time.

The dynamic versus static perspective underlying the cognitive and generative accounts, respectively, has important consequences. In cognitive linguistics, language dynamics both explains and necessitates the radial and gradient structure of categories. It provides a unified explanation of why a category may be used in more than one function, why different categories may be used to express the same function, and why some phenomena may exhibit properties that are exemplary of two (or even more) categories. As grammatical forms develop, acquiring and losing their formal and functional properties, they either develop towards the prototype of 
a category or develop away from it, approaching other categories and their prototypes. The formal and functional variability of a grammatical category (and language specific instantiations) results from a construction's ability to formally and functionally shift. The static perspective of synchrony assumed by generative grammar, by contrast, makes it virtually impossible to provide a unified account of the formal and functional variability of a grammatical category or its instantiations.

As demonstrated by studies within the fields of semantics, grammaticalization, and linguistic typology, shifts in meaning exhibited by constructions that belong to shared categories are not random. Thus, the functional potential of constructions of a certain class and their functional and formal connection to other categories are not accidental either. Language change, even though to an extent chaotic - as it depends on a great number of features of which some are extra-linguistics - is constrained and, relatively, predictable. Grammatical categories and language specific constructions tend to develop along certain paths (see for instance Bybee, Perkins and Pagliuca 1994; Dahl 2000; Hopper and Traugott 2003). These paths are crosslinguistically pervasive because their consecutive stages are cognitively motivated. Given this cognitive foundation and typological soundness, paths can be used to structure a category internally, and to provide dynamic, synchronic models of constructions.

Overall, cognitive linguists argue that the radial network model of grammatical categories is consistent with viewing language as complex adaptive system. The important aspect of such systems is that the "behavior" of their components depends not only on these components' internal properties (e.g. the compliance with the set of features postulated for the prototype) but also on the properties of the environment in which they are embedded. Grammatical categories are therefore situated. That is, they are connected to other categories and to the entire language system. Certainly, generative scholars do not negate the complexity of language. Nor do they avoid a holistic, systemic analysis of it. Quite the opposite - they bravely deal with language as an all-including system. However, instead of formulating a complex model of language (i.e., in the sense of complexity theory with its notions of dynamics, fuzziness and connectivity), they rather try to deal with it by further atomizing their analysis. They micro-analyze the language system, offering a compositional additive model of it (see for instance studies related to nano-syntax; Svenonius et al. 2009).

Members and postgraduate students of the Faculty of Arts and Social Sciences of Stellenbosch University (South Africa) have considered for the past decade some of the implications of the above-mentioned realities (and complexities) of language use, for the better understanding of a number of languages, in particular languages from the Niger-Congo family and from the Semitic branch of the Afro-Asiatic phylum. Some of these scholars have also been involved in a new 'direct' translation of the Bible in Afrikaans. In this project, they were challenged to "negotiate" with experts in Afrikaans concerning how to interpretively resemble the construal of the meaning of the LD construction and constituent order of Biblical Hebrew in Afrikaans. Given these challenges from the "real world of Bible translation" as well the hotly debated question in the field of Biblical Hebrew linguistics concerning what exactly constitutes a LD construction, a workshop was held on 6-8 September 2015 in the Department of Ancient Studies at the University of Stellenbosch. The aim of the workshop was to reach a better understanding of LD as a cross-linguistic category. To achieve this aim, the following research questions were formulated: 
1. When does a construction qualify as an instance of LD?

2. For what purposes do speakers use LD constructions in different languages and with what discourse-pragmatic function(s) are LD constructions associated across languages?

3. Which grammatical devices (or formal features) are typically involved in LD constructions?

4. How could the instances of LD in Biblical Hebrew be translated in target languages?

As a departure point of the research and the workshop, scholars in the fields of Afrikaans, Arabic, Biblical Hebrew, Greek (NT and LXX), Neo-Aramaic and Xhosa - as well as Polish at a later stage of the project - were invited to address the above-mentioned questions with reference (where possible) to a selected number of examples extracted from the Hebrew Bible. Most of these examples are regarded as canonical instantiations of the LD category found in Biblical Hebrew. To render the sample more diverse (and more representative) a few less canonical cases of LD in the Hebrew Bible have also been identified. Two scholars were additionally commissioned to approach their analysis of LD from a more general perspective, either typological-cognitive or generative. Papers were distributed beforehand and discussed in depth at the workshop and after it. The articles in this volume represent the outcomes of these discussions.

\section{Main findings}

The debates during the workshop and subsequently during the preparation of this volume have shown that all the contributors share, to an extent, a unified perspective. Although this perspective, in principle, corroborates the cognitive approach to language, it also aims to contribute to the better mutual understanding of cognitive and generative linguists. These common views can be summarized as follows:

1) LD is a radial category. It is organized around a prototype that is defined both formally and functionally. The category expands from its center of prototypicality (and its canonical instantiations) to the periphery that contains gradually less prototypical members (and their non-canonical instantiations). The LD prototype is a linguistic construct. It is derived from typological evidence given the frequency and saliency of certain properties that are crosslinguistically attested.

2) The canonical and non-canonical members of the LD category are connected via familyresemblance relationship. This implies that while two adjacent members necessarily share certain features, more distant members may not have any feature in common. Accordingly, no single formal criterion - be it syntactic or phonological - is essential or compulsory for LD to occur. This included the features of extra-clausal position (which is internally composite and scalar), pause (which is scalar) and resumption (whose presence is related to language idiosyncrasies). If anything, it is a phonological intonation pattern (e.g. pause) that seems to be the most pervasive trait that distinguishes LD from other categories and constructions. The same holds true to the functional profile of $\mathrm{LD}$, where the prototypical function need not be present for the construction to occur. 
3) LD is a dynamic category that is conceptually and, sometimes, diachronically related to other constructions, such as turn-constructional bi-propositional expressions on the one hand, and fronting (and subsequently unmarked word order) on the other. Especially relevant is the relation to fronting which may overlap with the LD category both in terms of form and function. This connection has an evolutionary foundation as fronting may constitute a further grammaticalization stage of LD. In some cases, where LD and fronting overlap, the intonation patterns may be the only feature distinguishing the two categories.

4) LD epitomizes the complex character of the language system, as well as the relational character of constructions and categories. The category status of a construction depends not only the construction's internal properties - in particular on complying (or not) with the criteria postulated for the prototype - but also on the properties of the language system that it is a part of.

In the subsequent discussion we will explain these findings in more details.

\subsection{LD as a radial category}

LD is a radial category (see for instance, Westbury 2016a; Andrason 2016c\&d; Andrason and Visser 2016) Its radial structure encompasses, and explains the compatibility with, a gamut of language-specific grammatical constructions that are employed to encode a range functions. The complexity of the LD category can be structured logically by postulating a prototype from which other members emanate. As a linguistic construct, the prototype does not exist in the real sense. It is a mental schematic postulation which has crosslinguistic (and thus empirical) foundation. It is posited given the frequency and saliency of certain features exhibited by language-specific constructions that are usually viewed as instances of LD.

Given that LD constructions are distinctive with respect to their function and form, the prototype of LD is defined both in functional and formal terms. With respect to its prototypical function, LD is used to mitigate a complex cognitive task, that of activating (or reactivating) a referent that, although identifiable, entertains a low degree of cognitive accessibility, while simultaneously identifying the referent's role - be it syntactic (e.g. subject, direct object, etc.) or pragmatic (e.g. topic or focus) - in the proposition.

With respect to form, the following attributes can be postulated for the typological prototype of LD:

1) It exhibits a mono-propositional structure.

2) The dislocated constituent is external to the matrix clause, being detached from it and placed sentence initially.

3) The dislocate is a noun phrase that is definite and appears in an unmarked case form, the so-called casus pendens (usually nominative or absolute).

4) The specification of the discourse-pragmatic and/or syntactic role is possible because of the presence of an overt element found in the matrix clause that is coindexed with the dislocate. This co-indexed element is a pronominal that exhibits a total identity link (i.e. co-referential), usually a resumptive pronoun.

5) The dislocate is marked by special intonation contour, typically a pause. 
Before we continue, it is worth clarifying that the second attribute listed above - the clauseexternal status of the dislocate - is itself a complex property, with dislocated constituents exhibiting varying degrees of detachment. However, on some occasions the dislocate may be overtly confirmed, either syntactically or semantically, as residing fully outside the boundary of the clause. For instance, some languages employ elements that function to mark the syntactic boundary of the clause (e.g. interrogative particles, exclamatory particles, discourse particles, conjunctions, etc.), such that any element positioned before these elements is considered external to the clause. On the other hand, co-referential resumptive pronouns may function to semantically mark the dislocate as external to the clause, since its inclusion would violate a fundamental semantic well-formedness condition: the same valency slot (i.e. theta-role) may not be filled twice in a single predication. However, in the absence of these overt features, the degree to which the dislocate is detached from the matrix clause may be only indirectly perceived.

The prototypical schema is the ideal representative of the LD category that emerges through the internalization of its most common and salient attributes. The prototype is ideal in the sense that it provides the highest degree of the overtness of the LD category, distinguishing it from any other grammatical structures to the largest extent. If languages-specific constructions fulfill all the features postulated for that prototype, they can be viewed as canonical, the most representative instantiations of the LD category. However, being the most representative does not imply that this type of LD construction is expected to be found in every single language, or that it should be the most common LD variant among all LD constructions a single language allows for. Indeed, in some languages fully canonical instantiations are less typical than noncanonical ones, while in other languages, instantiations of the typological prototype are impossible given the particular morpho-syntactic idiosyncrasies. For example, in languages with no morphological case, the criterion of casus pendens cannot be observed by definition, and in languages with no (or very scarce use of) pronouns, the feature of resumption is not fulfilled (e.g. in Maasai; see below). However, even in languages that have both grammatical case marking and use pronouns extensively, the most preferable LD construction does not need to exhibit these two features consistently (e.g. Polish; see Andrason 2016d).

This means, consequently, that many constructions within the LD category diverge from the typological prototype. That is, they exhibit various degrees of canonicity, ranging from lesscanonical to entirely non-canonical. The extent of this canonicity is directly correlated with the presence of attributes postulated for the prototype. The more attributes a given instantiation has, the more central the instantiation is in the category network. Inversely, if few features are observed, the construction is non-canonical, and consequently occupies a peripheral place in the network.

Critically, however, the LD category is more than its prototype. In fact, the prototype is only used to meaningfully structure the category; it is not employed as the definition of the category as a whole. Rather, the LD category consists of the entire network that expands from the center to the periphery, which includes canonical and non-canonical members. This understanding of LD makes it possible to include the array of divergent construction types found across languages that exhibit attributes of LD and to model this category in terms of a coherent whole. Within such a model, variations among constructions are preserved, and their asymmetrical status within the category network is represented. 


\subsection{Members of the LD category are connected via family resemblance relationship}

All of the instantiations of the LD category are connected via family-resemblance relationships (see Andrason and Visser 2016; Andrason 2016d). In general terms, this type of relationship implies the following: although two adjacent links of a chain always share certain properties, two remote links - i.e. those that are separated by a $x$ number of intermediary links - may not have any properties in common. Nevertheless, all of them belong to the same "family". Their resemblance lies in the chain itself and the $x$ reiteration of the adjacent similarity that connects two immediately successive links.

The family-resemblance relationship not only links non-canonical members of the LD category to its prototype, but it also establishes the connection among the non-canonical members themselves. This, in turn, ensures the coherence of the entire category network, relating its center to the periphery, and any section of the periphery to all other peripheral nodes of the network. This latter type of connection is especially relevant because, in extreme situations, two non-canonical members of the LD category fail to have in common any single feature that has been postulated for the prototype. That is, although each one of them exhibit some properties associated with the prototype, no property is simultaneously shared by both of them. In other words, while the relation from the prototype to any non-canonical member always implies some type of similarity (at least a few attributes must be preserved because otherwise the construction would not be included in the LD network), the mutual connection between some non-canonical members does not. For such members, it is (at least theoretically) possible that they do not involve any degree of similarity. Nevertheless, the family-resemblance relationship will warrant that all such instantiations still belong to the LD category.

The family-resemblance relationship that ensures the conceptual unity and soundness of the LD category (despite its internal variability, if not disparity), also implies that no single criterion is essential or compulsory for LD to occur, nor is any attribute postulated for the prototype deemed more important than any other. All attributes are qualitatively equal. This holds true for three attributes that are commonly viewed as the most salient and necessary attributes for LD: 1) extra-clausal position, 2) presence of resumption in the matrix clause, and 3) the phonological marking by means of a pause. Let us consider each of these in turn.

First, the extra-clausal position of the dislocate is often viewed as the defining attribute for LD (Lambrecht 2001). After all, left dislocation must involve a dislocation of an element from the matrix clause. However, the reality is far more complex. First of all, the extra-clausal criterion is itself a compositional characteristic, only detectable by the presence of other features. That is, while all the other properties postulated for the prototype are empirical, being directly observable, the extra-clausal position is derived via deduction from other, more basic empirical features. Moreover, the foundation of this attribute does not need to be a single empirical fact. It can involve - and usually does so - a set of facts, i.e. a number of other more basic empirical features. For example, the extra-clausal criterion of the dislocate may be overtly determined as a result of being placed before elements that, in a given language, explicitly mark the clauseboundary. These include specific clause-boundary markers, interrogative particles, exclamatory particles, discourse particles, conjunctions, etc. To render the matter even worse, such elements may themselves be polyfunctional. That is, even though in some instances they mark the limits of a clause, in others they may fail to do so. In cases where such elements are absent, the extraclause position may not be overtly observed, at least at the morpho-syntactic level. As a result, 
the extra-clausal status can only be extrapolated by analogy to examples where such markers are used. If such markers are polyfunctional (as for instance in Polish), such extrapolation should be taken with caution even though it is (more or less) likely. The criterion of extra-causal position is also related to the intonation pattern, as clause-boundaries are marked by a distinctive intonation in many languages. As we will see below, even though a pause is highly distinctive, and is usually present in most instantiations of LD, it is a scalar phenomenon. It can be long and clear, or short and subtle. In short, the extra-clausal status may be overt, or it may exhibit a gradient nature, being more or less detached from the matrix clause. In other words, rather than being formulated in terms of a binary opposition, the extra-clausal status is often one of degree.

The second salient feature that is often assumed to be essential for LD is resumption. This view can be challenged both on theoretical grounds (e.g. the family-resemblance structure of the LD category) and empirical grounds (e.g. observable crosslinguistic facts). With respect to the former, the family-resemblance relationship that unites the LD category does not require any feature, including resumption, to be compulsory, as stated above. The principle underlying this type of relationship is that remote members of a category do not necessarily share any traits. Moreover, this theoretical rationale is further substantiated by concrete empirical cases. That is, in some languages, the use of resumption in LD constructions is either facultative (e.g. in Polish; Andrason 2016d) or even impossible (e.g. in Maasai; Andrason and Karani forthcoming). This usually results from the idiosyncrasies of these language systems. In Polish for example, LD constructions commonly omits resumptive elements because their use is felt to be redundant. The sense of redundancy stems from the fact that the dislocate is inflected for case. In other words, since the role of the dislocate is indicated by the case inflection, no resumptive element is needed in the matrix clause.

In Maasai, overt resumptive elements are absent and even ungrammatical in most instances of the LD construction. This ungrammaticality stems from the particular morpho-syntactic constraints of this language. For instance, in Maasai, the pronominal argument of a verb (be it subject or any type of object) is typically not overtly expressed. The semantics of the verb makes it clear that a subject or an object is implied. Since pronominal arguments are unexpressed in most positions, the Maasai grammar makes it virtually impossible to use resumption in LD. As a result, the non-resumptive type of LD is not only optional in Maasai in most cases, it is de facto the only LD construction the language allows for (Andrason and Karani forthcoming). To conclude, resumption does not constitute a typologically defining feature of LD. Inversely, its absence does not warrant a sufficient reason to postulate a category that would be distinct from LD. Rather, in a language like Maasai, one is only encountering a less canonical instantiation of the typological prototype. However, non-canonical types, such as the non-resumptive variant in Maasai, may be the only type of construction possible, or the most frequent type in that language. In such languages, this typologically non-prototypical type will be the most "prototypical" construction for that particular language (see section 2.4 below).

Pause and/or determined phonological (tonal) patters are another class of features that characterize LD constructions. The research in this volume shows that in various cases, such patterns are the only feature that marks clause-boundary, thus indicating the dislocated status of the initial constituent(s) preceding the pause or intonation contour (see Khan 2016; Andrason and Visser 2016; Andrason 2016d). Indeed, if all the other morpho-syntactic criteria are absent, a pause or special intonation contour tends to be only attribute identifying the construction as 
LD. Indeed, in Polish, for example, a pause is the only property that distinguishes a LD structure from fronting (or even unmarked word order). Without the pause, these structures are identical.

The relevance of intonation should therefore not be minimized even for ancient languages such as Biblical Hebrew where the research has thus far focused primarily on morpho-syntactic properties of LD. The persistence of pause and other distinctive phonological patterns derive from the diachronic and conceptual origin of LD as a "recognition-search-sequence" (CouperKuhlen 2011). LD constructions commonly develop or have their conceptual foundations in spontaneous discourse routines in which the (re)activation of a referent and the identification of its function take place in three distinct dialogue turns, where the first utterance (i.e. turn) is used to (re)activate the referent, and the third utterance is used to specify the referent's role in within the proposition. In between the first and third utterance, the speaker pauses so that the hearer can acknowledge that (s)he has successfully (re)activated the referent. This acknowledgement constitutes the second turn in the sequence (see Westbury 2016b of this volume for further discussion). Critically, the LD construction derives cross-linguistically from this three-stage turn management system for the (re)activation and role-identification of a referent (Geluykens 1992). As this turn-system gradually grammaticalized into the LD construction, the pause inherited from the second turn in the dialogue became a typical feature of the construction. Moreover, the pause also became shortened since no overt acknowledgement was expected on the part of the hearer. In short, the (re)activation of the referent and the identification of its role grammaticalized from a tripartite proposition dialogue into a mono-propositional construction. Furthermore, different LD constructions may differ with respect to the length of pause-the pause being more noticeable in some constructions than in others. The variation in the length of the pause is due, in part, by the gradual nature of language change and the equally gradual development from LD to fronting to unmarked word order (see section 2.3 below; see also Andrason and Visser 2016; Andrason 2016d). However, is critical to remember that, although it is highly relevant for $\mathrm{LD}$, the pause is a gradient phenomenon, and should therefore not be considered a necessary feature of LD. In other words, it is possible, albeit non-prototypical, for LD to occur without a pause (see Andrason 2016d).

The formal profile of LD discussed thus far - comprised of family-resemblance relationships which form a radial network of overlapping construction types - also applies to the functional profile of the LD category. That is to say that the prototypical function (i.e. the (re)activation of a minimally accessible referent) is not essential for LD to occur. Indeed, there are various instances where constructions that are fully or highly canonical from a formal perspective (i.e. they exhibit all the features postulated for the LD prototype or most of them) do not (re)activate an identifiable referent that entertains a low degree of accessibility. In such cases, either the referent is fully accessible or other functions are profiled (e.g. contrast). As a result, an LD construction that is non-canonical with respect to its function may (to a degree) functionally overlap with other constructional categories (e.g. fronting).

As is perhaps obvious, the form and the function of LD are closely related given the iconicity of this structure. That is, the prototypical form of the LD construction reflects its prototypical function, and vice versa. As the form and meaning of LD cannot be entirely separated and treated independently from each other, the divergence from the formal prototype will almost automatically cause a lesser degree of prototypicality of the function (see Andrason 2016c\&d). 
To conclude, in light of the gradient nature of the LD category and its prototype effects, there is no need to create new ad hoc categories (e.g. 'extreme topicalization' or 'extreme topic fronting'; Holmstedt 2014) each time a certain feature postulated for the LD prototype (be it formal or functional), or even a group of them, is not instantiated. Instead, all such divergent constructions can be viewed as non-canonical members of the LD category, with varying degrees of prototypically. The understanding of the LD category as a radial network comprised of family-resemblance relationships offers an alternative to the proliferation of labels that leads to fragmentizing linguistic reality into separate boxes, and to losing the unity and relatedness of grammatical phenomena. It enables us to maintain the coherence (or unity) of all instantiations of LD encountered across languages, while at the same time preserving their distinctiveness and uniqueness.

\subsection{LD is a dynamic category related conceptually and diachronically to other categories}

At this juncture, it is prudent to offer some clarification a couple of issues discussed above. First, the discussion thus far has emphasized the importance of understanding the LD category as a radial network of constructions that are related (to some degree) via family-resemblance to a typological prototype. However, it is important to clarify that the LD category, as described here, does not exist in isolation from other constructional categories. On the contrary, it is closely related to other constructional categories, in particular, bi-clausal presentational constructions, and fronting (see Khan 2016; Andrason 2016c\&d; Andrason and Visser 2016).

Another point of clarification concerns the directionality of the relations within the network. In some cases, the direction leads from the center (the prototype) to the periphery (least prototypical). Yet, the inverse may also occur, the direction pointing from the periphery to the center. The reason for this lies in the diachronic, and therefore dynamic, nature of the category.

Different types of LD found across languages - and presented as members of a radial network - represent different stages of a conceptual and diachronic continuum. This continuum ranges from the turn-management dialogue at one end of the diachronic continuum, to fronting, and ultimately to unmarked word order at the opposite end of the continuum (Khan 2016; Andrason 2016c\&d; Andrason and Visser 2016). The LD category exists within the two poles on this continuum, where each pole represents a posterior and anterior evolutionary state, respectively. To be exact, on the one hand, LD represents the furthest degree of grammaticalization turnmanagement dialogic structures. As discussed above, such turn-management structures take the form of a tripartite dialogic structure prototypically consisting of three turns. In the first turn, a speaker introduces, or (re)activates a referent. The second turn consists of a pause, where the speaker waits for the hearer to acknowledge the identification of the referent, and in the third turn, an utterance is spoken which specifies the referent's role in a proposition. As grammaticalization ensues, these dialogic structures are re-packaged as mono-propositional LD constructions uttered only by speaker. Since no hearer acknowledgment is expected (i.e. the second turn), the pause is shortened. Furthermore, the referent's role in the proposition is indicated by an overt resumptive pronoun. Thus, the construction approaches the LD prototype. Moving further down the grammaticalization cline, LD begins to lose various prototypical attributes. For example, the pause may become extremely short, to the point where it is unperceivable, thus obscuring its dislocated position (see Andrason and Visser 2016; Andrason 2016d; see also Couper-Kuhlen 2011). At this stage, the dislocate may also become inflected 
for case, which overtly indicates its role in the proposition, thus rendering the presence of resumption unnecessary. At this point, the construction has begun to approximate the category of fronting.

Given this diachronic dimension, the direction of linkage that relates different constructions to the LD prototype is different. One class of constructions gradually increases its extent of LD canonicity, increasingly reflecting the LD prototype. In other words, these constructions move towards the center of the LD category. In contrast, the other class of constructions gradually reduces its compliance or similarity with the LD prototype - these members of the continuum depart from LD heading towards the category of fronting (Andrason 2016c\&d; Andrason and Visser 2016).

As a result, all types of LD constructions can be imagined as travelling along a path on which the prototype of LD constitutes only one of the myriad of possible stages. The extremes that confine this continuum correspond to the source of LD and its ultimate outcome (i.e. fronting followed by unmarked word order). Thus, LD can, itself, be viewed as an intermediary conceptual and diachronic stage between two other constructional categories which form a wider dynamic phenomenon in grammar. This phenomenon is related to changes in word order and the development of pragmatically driven discursive patterns towards more routinized morpho-syntactic structures (Givón 1971, 1976, 2016; Du Blois 1985; Haiman 1985; Hopper and Traugott 2003; Fischer 2010; Van Gelderen 2011).

Furthermore, the scale that dynamically links LD with other grammatical categories makes reference not only to formal properties of various constructions but also to their functions. In its prototypical function, LD is used to mitigate a cognitively complex and costly task: it (re)activates a referent that, albeit identifiable, entertains a low degree of accessibility, while simultaneously specifying this referent's syntactic or discourse-pragmatic role in the proposition. These two grammatical jobs are accomplished in a mono-propositional structure. Such a function constitutes a later grammaticalization stage than that accomplished by tripartite dialogic structures on the one hand, and an earlier stage than mono-clausal functions of focality and topicalization typically accomplished by fronting.

As result of the above described radial network model, as well as the dynamic nature of language change, it is possible for language-specific constructions to exhibit traits that are typical of two prototypes and thus belong to the two category networks. In particular, the relation and compliance with any two prototypes is inversely correlated - as the similarity with one prototype increases, the similarity with the other decreases. Given the unidirectionality of grammaticalization, it is hypothesized that traits of less advanced prototypes gradually give place to the characteristics of more grammaticalized prototypes. Critically, however, some mixed cases are located at fuzzy boundaries where it is difficult (or impossible) to classify a construction either as one type or another. Accordingly, a single construction may be related to or be used as two different categories in two different contexts. Or in one context, it may lend itself to multiple ambiguous interpretations, each related to one of the two possible categories (see Andrason 2016c\&d; Andrason and Visser 2016).

The results of the analyses in this volume principally revealed a connection between the LD and fronting (and unmarked word order) confirming the evolutionary relationship between these two categories, the latter possibly being a further grammaticalization stage of the former. 
The evidence also seems to suggest a partial overlap (i.e. fuzzy boundaries) between the two categories. This results from family-resemblance relationship that ensures the unity of their radial networks and by the gradualness of language change. The data also indicates that, in some cases, intonation patters may be the only features distinguishing the two categories and linking them to their respective prototypes.

All of this can be illustrated by means of a color spectrum presented in Figure 1 below, that shows the conceptual relation between the white color and the black color. Let us imagine that the path along which various LD construction travel and on which they can be located is such a continuum. It ranges from the prototype of turn-management dialogues (white) to the prototype of mono-clausal fronting (black) through the prototype of mono-propositional but not mono-clausal LD (red). Even though the two opposite edges of this continuum - represented as white and black colors - most likely do not have any features in common, their connection can be demonstrated. This is possible through a gamut of intermediate successive steps. One such step is the LD prototype, which is itself separated from the two other prototypes by a series of transition phases. The constructions (i.e. colors) on the path are not always directly connected via shared attributes. Rather they are connected as a result of the reiteration of intermediary adjacent links where the direct conceptual relationship is clear and cognitively motivated. Thus, the shorter distant separating two constructions (or two colors) on the scale is, the more easily their conceptual relationship and similarity can be recovered.

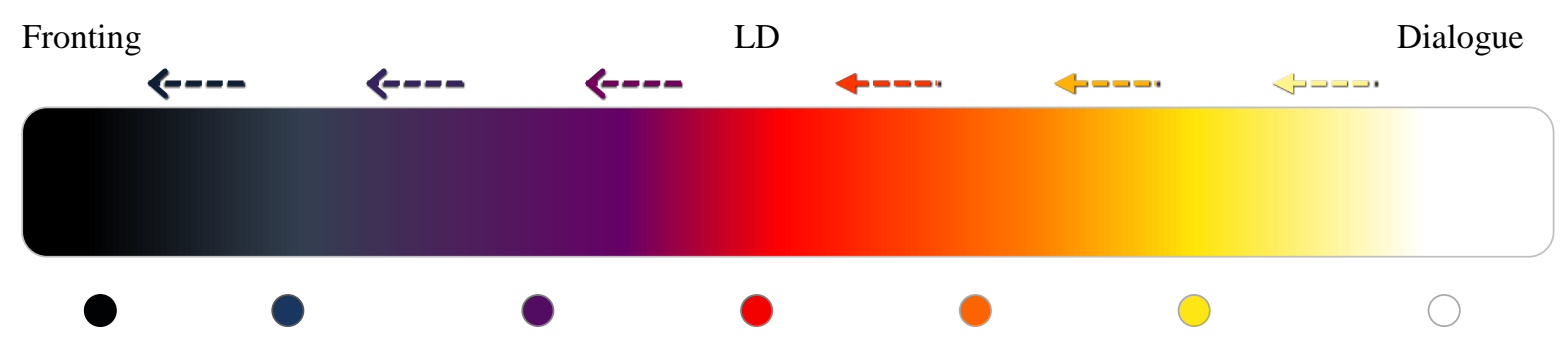

Figure 1: LD within a grammatical continuum ${ }^{1}$

Accordingly, this means that the conceptual link between the LD construction (red) and the two opposite poles of the continuum (white and black) can be recovered more straightforwardly than the direct relation between the two edges (white and black). Indeed, LD exhibits certain features that relate it to turn-management structures. Such inherited traits are for instance intonation patters and pause, as well as the function of the (re)activation of a referent and the subsequent identification of its role. LD also possesses features that can be recognized in fronting, e.g. the syntactic position of the initial referent in the front most position.

Two additional facts are important to note with respect to the scale in Figure 1. First, the progression from one type to another (i.e. from one shade of color to another) is unidirectional. This stems from the unidirectionality of grammaticalization and its irreversibility (see Bybee, Heine, and Pagliuca 1994; Heine 2001; Andrason 2016a, 2016b). Second, even though one may

\footnotetext{
${ }^{1}$ In this Figure the ultimate outcome corresponds to fronting. However, the whole scale depicted here constitutes a fragment of an even larger scale leading to unmarked word order. In general, in grammar, everything has its conceptual and diachronic predecessor as well as its successor. Thus, any cline is an interminable cycle.
} 
fragmentize the scale into separated boxes, of which each represents a "distinct" category (e.g. yellow, orange, red, purple, blue and black, note the circles in Figure 1 above), in reality, a boundary-free continuum exists in which constructions gradually transition from one pole to the other.

The explanatory power of the scale posited above is not exhausted at the diachronic level, or the category level. Put differently, the scale not only schematizes the diachrony of various turnmanagement, LD and fronting structures (e.g. by organizing them into a path of successive grammaticalization stages and thus by conceptually relating the three different prototypes and their category networks), it can also be used to structure the polysemy of a single construction in a language. That is, one can employ this scale to represent a given language-specific construction dynamically at a synchronic level, portraying its polysemy or polyfunctionality as an evolutionary phenomenon.

\subsection{LD epitomizes the complexity of language}

LD epitomizes the complexity of language, where complexity is understood according its use in complex-systems theory (cf. Andrason 2016a). On the one hand, the internal structure of a language-specific LD construction, its category status, and its place in the language-system is extremely convoluted, involving a large number of elements. On the other hand, the behavior of a LD construction, including its category rank, depends not only this construction's internal properties but also on the properties of other constructions, not to mention the (entire) system that embeds it (regarding the situatedness of grammatical constructions, see Andrason 2016a, 2016b).

A language-specific LD construction is an extremely complex object. To begin with, a single occurrence of an LD construction in a given language reflect the typological prototype to a lesser or greater degree. In other words, the construction may be a total match with the prototype, in which case all the features postulated for the prototype are instantiated, or the opposite may occur, in which very few such properties, or even not a single one of them, is present. Or the construction may fall somewhere in between these two extremes (see Andrason 2016d).

Similarly, the function of an instantiated construction in a particular context can approximate the LD prototype fully or only to a certain degree. That is, the LD construction may express the function associated with the prototype, or it may be colored by other shades of meaning, or it may even be used to accomplish an entirely different task. Both gradient types of compliance are necessitated by the radial structure of the category network and the nature of language change (Westbury 2016a; Andrason 2016c; Andrason and Visser 2016).

Second, the complexity increases when a given language-specific LD construction is analyzed in its totality, i.e. when one formulates the model or the definition of a form that would be valid for all its uses. Grammatical constructions - not only lexemes - are inherently polysemous or polyfunctional (Falkum and Vicente 2015). They can convey more than one function in a given language. No less important is their common poly-morphism, or ability to appear in different morpho-syntactic variations (consider allomorphs or syntactic alternative structures, e.g. going to versus gonna; Hopper and Traugott 2003). This implies that any LD construction, viewed as a holistic category, should be able to express more than one meaning and adopt more than one 
formal appearance. Qualitatively, it should span a part of a radial network and/or a section of the grammaticalization cline. This is again necessitated by the mechanisms of language change and the nature of grammaticalization. Overall, the reduction of a language-specific LD construction to a single label (i.e. only one form and/or only one function) is impossible and contrary to the very character of meaning shift and language development.

Third, the complexity of a language-specific LD construction is further incremented by quantitative effects (see Westbury 2016b). That is, each type of use (related to formal and functional characteristics) that is mapped as a point in the radial network and/or grammaticalization cline can be instantiated with different frequencies of use. This, in turn, creates (or reflects) different prototypicality effects for that construction. Those uses that are occur most often, and are less contextually limited are associated with that form by the speakers. Those that are occur less often, and are constrained to particular context are viewed by the speakers as special or irregular. ${ }^{2}$

As a result, an instantiated LD construction in a given language can match the LD prototype to different degrees, in different contexts, and with different frequencies of use. This complexity is overwhelming. It also makes it virtually impossible that the behavior and the category status of two LD constructions (e.g. from two different languages) be perfectly identical. In our view, the best way to conceptualize and represent the complexity of LD constructions is by using radial-network and dynamic-path models organized around prototypes and unified by means family-resemblance relationships, and by additionally acknowledging the relevance of frequency for the internal structure of their polysemy (polyfunctionality) and polymorphism.

A final correlation between LD and complex systems concerns the relation of the LD category to other grammatical categories. A language-specific LD construction (as it is also true of the LD category in general; see section 2.3 above) is not an isolated phenomenon that exists on its own, in a type of grammatical void. As anything in language, a LD construction is inherently situated. Therefore, it can only be adequately comprehended if other constructions and the entire language system is taken into consideration (see for instance, Andrason and Visser 2016). Of course, it is impossible to include everything in a linguistic analysis. Rather, the part of the language under analysis must be framed. Nevertheless, aspects of the broader language system that directly relates to the LD construction should be acknowledged.

The situatedness of LD can be observed, at least, in two types of phenomena. First, even though the internal properties of a LD construction-and in particular its compliance with the LD prototype-have not been modified (i.e. the LD from exhibiting all such features), other changes in the language (e.g. the development of object agreement) may critically affect that constructions position in the radial network, and its relation to other grammatical categories (e.g. fronting; Khan 2016; Andrason and Visser 2016). Second, certain language specific idiosyncrasies may make it impossible for a LD construction to exhibit all the features postulated for the prototype. As a result, instantiations that, from a crosslinguistic perspective, appear as less canonical or entirely non-canonical, may nevertheless be the most common or even the only possible type of LD construction that a given language allows for. This suggests

\footnotetext{
${ }^{2}$ In most cases, the construction's prototypicality is related to frequency of each of its different uses. It should, however, be noted that other factors, such as productivity, may also contribute a given use being considered prototypical, and that frequency itself is a complex concept (Schmid 2010; Glyn 2010; Gries and Divjak; Stefanowistch 2010).
} 
that the cross-linguistic prototype and a language-internal "prototype" need not necessarily overlap (Andrason 2016d; see also Andrason and Karani forthcoming). ${ }^{3}$

\section{Invitation to the articles}

As a typologically universal phenomenon, the LD construction has received detailed analysisfrom both formal and functional-perspectives, within a number of genetically and areally diverse languages. Therefore this volume will begin in the first article, Westbury (2016a), with a general overview of this cross-linguistic research, concentrating on: 1) the comparison of syntactico-semantic features of LD across languages, 2) the generalized cross-linguistic patterns and categories attested for LD, and 3) the explanations offered for LD in terms of its motivation and function in discourse. Accordingly, the article will proceed in two parts. The first part will entail a brief survey of the syntactic and semantic attributes that have established LD as a typological category. In light of these attributes, linguists generally distinguish between two broad types of LD on the basis of particular syntactic patterns and constraints. Thus, a general description of these types is provided, along with a brief description of several less prototypical LD types. The second part of the article will focus on the explanation of LD both in terms of the cognitive and contextual constraints that motivate its use in discourse, as well as the communicative goals and pragmatic effects achieved by the construction in particular contexts.

In the second article, Oosthuizen (2016), the syntax of LD is examined from a generative linguistic perspective. In Government \& Binding theory and early versions of Minimalist Syntax, the left-dislocated expression is conventionally taken to be base-generated in its sentence-initial surface position and the resumptive pronoun in some other position in the structure. The establishment of an (obligatory) coreferential relationship between these expressions is usually ascribed to a special binding mechanism, A-bar binding, though this issue is seldom explicitly addressed in LD-studies. The aim of this paper is to present, in broad outline, an alternative analysis of LD-constructions, one that incorporates the core hypotheses of the nominal shell analysis of coreferential constructions. On this analysis, the resumptive pronoun and the referring expression that is to serve as its antecedent are base-generated in a nominal shell structure which is headed by a presentational focus light noun, a functional category belonging to a natural class of identificational elements. The coreferential relationship between the two expressions is established within this structure by means of phi-feature valuation. The antecedent is subsequently raised into the left-periphery of the sentence, where it surfaces as the left-dislocated expression. It is claimed that such an analysis can account for the phenomenon of obligatory coreferentiality in LD constructions in terms of formal devices that are either already provided by or compatible with the basic assumptions and concepts of Minimalist Syntax. A proposal is also put forward to account for the word order in LD constructions, specifically the fact that left-dislocation does not bring about (surface) subjectverb inversion in V2 languages such as Afrikaans.

The third article, Westbury (2016b) presents a functional profile of LD in Biblical Hebrew-in particular, the Hebrew of the Torah and Former Prophets (Genesis-2Kings). As a precursor, however, an abbreviated syntactico-semantic description of LD constructions within the

\footnotetext{
${ }^{3}$ Complex systems are also characterized by their dynamics and fuzziness. See previous sections for further discussion.
} 
aforementioned corpus is provided. This description consists of seven overlapping constructional schemas (i.e. construction types) that form a radial network around a typologically prototypical schema. Accordingly, each schematic type is more or less prototypical depending on its family resemblance (i.e. shared attributes) to the prototype. In light of this formal profile, and of the fact that grammatical constructions are equal parts form and function, the remainder and central focus of the paper will entail a detailed functional explanation of LD. This functional profile will consist of two complementary parts: 1) the central factors motivating the use of LD, and 2) the prototypical and non-prototypical discoursepragmatic functions achieved by the construction in discourse. Together with the formal description, this functional explanation reveals a textured profile of the LD category, one that consists of a unified radial network of overlapping constructional types.

Turning to a modern North-Eastern Semitic language, the fourth article, Khan (2016), examines LD constructions in Neo-Aramaic dialects spoken across a wide area encompassing northern Iraq, north-west Iran, south-eastern Turkey, Armenia and Georgia. In these spoken dialects, a distinction is made between two major types of LD. The first type, referred to as LD1, is characterized by an initial item that is prosodically and grammatically integrated with what follows by an intonation group boundary. Additionally, the initial item is resumed in the clause by a pronominal affix, as opposed to an independent pronoun or a full nominal. Such initial items have all the semantic and functional properties of normal grammatical subjects. A second type, referred to as LD2, is characterized by an initial item that is less integrated prosodically and/or structurally with what follows. This includes cases where the initial item is separated from what follows by an intonation group boundary. Another strategy for disjoining the initial item from the rest of the clause is the resumption of the initial item by an independent pronoun. Moreover, an initial item may be less integrated into the clause than LD1 constructions is where the resumptive element is a full nominal rather than a pronoun. From a functional perspective, an initial item in a LD2 structure is restricted to nominals that are topical, i.e. they function as the informational pivot or starting point of the following clause and typically their referent is identifiable from the context. The initial item of an LD1 structure, however, can have a variety of other types of status, including narrow focus. In this respect they correspond functionally to clause-initial subjects. When a clause initial item has topical status, whether it be subject, an LD1 item or an LD2 item, the basic function of the construction is to express the onset of a discourse section and, if it occurs within the body of the discourse, a disjunction of some kind from what precedes. This includes not only topic shift, but also other types of discourse shifts, such as foreground to background or change in the level of description. In some cases, an LD1 construction is more normal than a construction with the grammatical subject in initial position, and indeed in some cases it is obligatory. This has given rise to diachronic change whereby the original grammatical subject of the construction has been reanalyzed as having a different syntactic status.

Pivoting to yet another Semitic language, the fifth article, Andrason (2016c), demonstrates that the typologically prototypical function associated with LD is conveyed in Arabic by a set of structurally divergent LD constructions. In the analyzed corpus, these constructions are of two main types: 1) Clitic LD, where the dislocated NP either appears in casus pendens or is marked by markers 'ammā or 'inna, and 2) Subject LD, where the subject pronoun can be overly expressed or not. Some LD constructions formally and/or functionally overlap with other grammatical forms-in particular, fronting constructions. Overall, the absence of a feature postulated for the LD prototype does not automatically imply the necessity of postulating a new 
category, different from LD, and/or viewing that form as fronting. The overlap between LD and fronting is explained as a typical effect of language complexity that can be dealt with if the system of forms and meanings is understood as fuzzy.

The sixth article, Andrason \& Visser (2016), moves away from the Semitic language family, examining LD in the Bantu language of Xhosa. In particular, this article demonstrates that the status of Clitic LD (=CLD) in Xhosa is a result of the mosaic evolution of Xhosa grammar. It emerges as an accumulation and combination of two or more individual, distinct and, at least, initially separated developments and characteristics-LD sensu stricto and Object Agreement $(=\mathrm{OA})$. This view enables the authors to propose a possible solution to the problem of whether the CLD structure in Xhosa (and Nguni) is an instantiation of LD (and its prototypical function as posited by Westbury (2014)) or fronting (and its functions of topic or focus). The CLD structure is employed to accomplish the following two tasks, with the first finding its origin in the original LD construction, and the second arouse from the OA cycle. The mosaic character of LD in Xhosa, in turn, demonstrates the situatedness of LD. LD is determined not only by its own evolutionary baggage (i.e. the source from which it has developed) but also by the dynamics of the environment in which it has been embedded (i.e. the properties of other constructions).

The seventh article, Van der Merwe (2016), examines various issues involved in the translation of LD from source to target languages within the field of Bible Translation. In terms of the theoretical framework of an influential recent model of Bible translation, LD can be regarded as a "communicate clue" that translators must try to interpretively resemble in their target text translation. This article investigates how twenty translations (fifteen English, three Afrikaans, one German, and one Dutch) have interpretively resembled (or not) nine prototypical constructions, and one less prototypical one, from the book of Genesis. It is shown that, firstly, translations on the formal equivalent pole tend to interpretively resemble LD constructions. Moreover, if the LD reflects the typological prototype, this tendency is displayed even by some translations towards the functional equivalent pole. Secondly, even in the case of prototypical instances, translations on the functional equivalent pole tend not to interpretively resemble the construction. In these cases, it could be argued that they are not serving the very goal that they, as a rule, want to accomplish - that is, to provide readers with a translation that is easy to read and process. Thirdly, the structure of English, Afrikaans, and Dutch-in contrast to Germanoften appears to require a construal that does not formally reflect the pronominal resumption of the LD constituent in the matrix clause. Fronting the LD constituent is often used, and sometimes a pause after the fronted (i.e. then dislocated) constituent is signalled by means of a comma or a dash. These findings concur with those of some of the other papers in this volume. Resumption, for example, is not always the primary distinctive feature of a LD construction; a tonal pause between the LD and its matrix clause may also suffice.

As a final contribution to this volume, Andrason (2016d) entails an analysis of the use of resumption in LD constructions in Polish. This article shows that Polish LD constructions omit resumptive elements more commonly than they employ them. The absence of resumption is a part of a more general phenomenon in Polish-the gradient nature of LD constructions ranging from more canonical (similar to the crosslinguistic prototype) to less canonical (more distant from the prototype), and their relation to fronting. As a result, this article provides further evidence for the facultative status of resumption in the crosslinguistic LD category, and for the universal, formal and functional, relationship between LD and fronting. 
This volume concludes in Westbury \& Andrason (2016) where we briefly highlight several specific issues in LD research that are in need of further investigation, including, among others: 1) a coherent, empirically grounded mapping of the diachronic processes (e.g. competing motivations, internal/external constraints, etc.) that have led to such astonishing similarity and drastic variation-both syntactically and functionally-across languages, 2) further inquiry into the cross-linguistic correlations between specific syntactic LD types and particular discoursepragmatic functions, and 3) the precise formal and functional relationship between LD and other, typologically attested, constructional categories (e.g. fronting, vocatives, rhetorical questions, etc.). Lastly, we close with a brief note on the broader issue of word order variation as it pertains to the LD category, as well as related constructional categories (e.g. fronting). In short, we propose an alternative approach that does not rely on the notions of basic/default word order or markedness-the problems of which have been observed by Payne 1985, Siewierska 1988, Mithun 1992, Dryer 1995, 1997, inter alia. Rather, we contend that various word order types are best understood as entrenched and highly grammaticalized schemas. They are not constructed online from some basic or unmarked configuration each time they are uttered, but are instead wholly available to speakers in their totality. In other words, as with other grammaticalized constructions, word order types are available to speakers as prêt-à-porter garments that need not be stitched together each time they are used.

\section{References}

Andrason, A. 2016a. A Complex System of Complex Predicates: Tense, Taxis, Aspect and Mood in Basse Mandinka from a Grammaticalization and Cognitive Perspective. PhD dissertation, Stellenbosch University.

Andrason, A. 2016b. From vectors to waves and streams: An alternative approach to semantic maps. Stellenbosch Papers in Linguistics 45. 1-29.

Andrason, A. 2016c. Left Dislocation in Arabic: The complexity of form and meaning. Stellenbosch Papers in Linguistics Plus 50. 111-138.

Andrason, A. 2016d. To resume or not to resume: Some remarks on 'resumption' in left dislocation constructions in Polish, and its relevance for Biblical Hebrew. Stellenbosch Papers in Linguistics Plus 50. 185-199.

Andrason, A. and M. Karani. forthcoming. Syntactic gradience: The non-resumptive Left Dislocation in Arusha (Maasai). Studia Linguisticae Universitatis Iagellonicae Cracoviensis.

Andrason, A. and M.W. Visser. 2016. The mosaic evolution of Left Dislocation in Xhosa. Stellenbosch Papers in Lingusitics Plus 50. 139-158.

Bybee, J., R. Perkins and W. Pagliuca. 1994. The Evolution of Grammar. Chicago: The University of Chicago Press.

Couper-Kuhlen, E. 2011. Grammaticalization and conversation. In H. Narrog and B. Heine (Eds.) The Oxford Handbook of Grammaticalization. Oxford: Oxford University Press. pp. 424-437. 
Dahl, Ö. (Ed.) 2000. Tense and Aspect in the Languages of Europe. Berlin: Mouton de Gruyter.

Dryer, M.S. 1995. Frequency and Pragmatically Unmarked Word Order. In P. Downing and M. Noonan (Eds.) Word Order in Discourse. Amsterdam: Benjamins. pp. 105-135.

Dryer, M.S. 1997. On the Six-Way Word Order Typology. Studies in Language 21. 69-103.

Du Bois, J. 1985. Competing motivations. In J. Haiman (Ed.) Iconicity in Syntax. Amsterdam: John Benjamins. pp. 343-365.

Falkum, I. and A. Vicente. 2015. Polysemy: Current perspectives and approaches. Lingua 157. $1-16$.

Fischer, S. 2010. Word-order Change as a Source of Grammaticalisation. Amsterdam: John Benjamins.

Geluykens, R. 1992. From Discourse Process to Grammatical Construction: On LeftDislocation in English. Amsterdam: John Benjamins.

Givón, T. 1971. Historical syntax and synchronic morphology. Chicago Linguistics Society Proceedings 7. 394-415.

Givón, T. 1976. Topic, pronoun and grammatical agreement. In Ch. Li (Ed.) Subject and Topic. New York: Academic Press. pp. 149-188.

Givón, T. 2016. The diachrony of pronominal agreement: In Ute and maybe elsewhere. In E. van Gelderen (Ed.) Cyclical Change Continued. Amsterdam: John Benjamins. pp. 251-286.

Glyn, D. 2010. Corpus-driven cognitive semantics introduction to the field. In D. Glyn and K. Fischer (Eds.) Quantitative Methods in Cognitive Semantics: Corpus-Driven Approaches. Berlin: De Gruyter Mouton. pp. 1-41.

Haiman, J. (Ed.) 1985. Iconicity in Syntax. Amsterdam: John Benjamins.

Gries, S. and D. Divjak. 2010. Quantitative approaches in usage-based cognitive semantics: myths, erroneous assumptions, and a proposal. In D. Glyn and K. Fischer (Eds.) Quantitative Methods in Cognitive Semantics: Corpus-Driven Approaches. Berlin: De Gruyter Mouton. pp. 333-353.

Heine, B. 1997. Cognitive Foundations of Grammar. Oxford: Oxford University Press.

Holmstedt, R. D. 2014. Critical at the margins: Edge constituents in Biblical Hebrew. KUSATU 17. 109-56.

Hopper, P. and E. Traugott. 2003. Grammaticalization. Cambridge: Cambridge University Press. 
Janda, L. 2015. Cognitive linguistics in the year 2015. Cognitive Semantics 1. 131-154.

Khan, G. 2016. Left Dislocation in North-Eastern Neo-Aramaic Dialects. Stellenbosch Papers in Linguistics Plus 50. 91-110.

Mithun, M. 1992. Is Basic Word Order Universal? In D. L. Payne (Ed.) Pragmatics of Word Order Flexibility. Amsterdam: Benjamins. pp. 15-61.

Oosthuizen, J. 2016. On Establishing Coreference in Left-Dislocation Constructions. Stellenbosch Papers in Linguistics Plus 50. 47-63.

Payne, D. L. 1985. Review of Word Order Universals by J. A. Hawkins. Language 61. 462466.

Schmidt, H. J. 2010. Does frequency instantiate entrenchment in the cognitive system? In D. Glyn and K. Fischer (Eds.) Quantitative Methods in Cognitive Semantics: Corpus-Driven Approaches. Berlin: De Gruyter Mouton. pp. 101-136

Siewierska, A. 1988. Word Order Rules. London: Croom Helm.

Stefanowitsch, A. 2010. Empirical cognitive semantics: Some thoughts. In D. Glyn and K. Fischer (Eds.) Quantitative Methods in Cognitive Semantics: Corpus-Driven Approaches. Berlin: De Gruyter Mouton. pp. 335-380.

Svenonius, P., G. Ramchand, M. Starke and K. Taraldsen. 2009. Nordlyd 36.1. Special Issue on Nanosyntax. CASTL: Tromsø.

Van der Merwe, C.H.J. 2016. Left Dislocation and its translation in some Germanic languages. Stellenbosch Papers in Linguistics Plus 50. 159-184.

Van Gelderen, E. 2011. The Linguistic Cycle. Language Change and the Language Faculty. Oxford: Oxford University Press.

Westbury, J. 2016a. Left Dislocation: a typological overview. Stellenbosch Papers in Linguistics Plus 50. 21-45.

Westbury, J. 2016b. A Functional Profile of Left Dislocation in Biblical Hebrew. Stellenbosch Papers in Linguistics Plus 50. 65-90.

Westbury, J. and A. Andrason. 2016. Left dislocation: towards a new horizon. Stellenbosch Papers in Linguistics Plus 50. 201-204. 